\title{
Time to bust common osteoarthritis myths
}

Daniel W. O'Brien PhD

Senior Lecturer, Physiotherapy Department, School of Clinical Sciences, Auckland University of Technology, Auckland, New Zealand

Cathy M. Chapple PhD

Senior Lecturer, School of Physiotherapy, University of Otago, Dunedin, New Zealand

Jennifer N. Baldwin $P h D$

Post-Doctoral Fellow, School of Clinical Sciences, Auckland University of Technology, Auckland, New Zealand

Peter J. Larmer DHSC

Head of School, School of Clinical Sciences, Auckland University of Technology, Auckland, New Zealand

\section{ABSTRACT}

Several common beliefs about osteoarthritis held by people living with the condition and some clinicians are discordant with current evidence and can hinder effective management. Therefore, providing information about the disease and its mechanisms could lead to better management of people with osteoarthritis. This paper addresses the seven most common myths surrounding osteoarthritis relating to its causative factors, pathology, assessment and management. We present the evidence to refute these misconceptions and argue that physiotherapists are in an ideal position to provide education to people with osteoarthritis. Ultimately, physiotherapists can play a central role in the provision of care for people with osteoarthritis.

O'Brien, D. W., Chapple, C. M., Baldwin, J. N., \& Larmer, P. J. (2019). Time to bust common osteoarthritis myths. New Zealand Journal of Physiotherapy, 47(1), 18-24. https://doi.org/10.15619/NZJP/47.1.03

Key Words: Osteoarthritis, Beliefs, Attitudes, Treatment, Misconceptions

\section{INTRODUCTION}

Osteoarthritis is the most common form of arthritis and, typically, affects the joints of the knees, hips, spine and hands (Hochberg, Silman, Smolen, Weinblatt, \& Weisman, 2015; Palazzo, Nguyen, Lefevre-Colau, Rannou, \& Poiraudeau, 2016) People with osteoarthritis often experience pain, joint stiffness and weakness; this can affect their mobility, function, ability to work, mental well-being and independence (Hall et al., 2008; Hawker et al., 2010, 2011). Approximately 670,000 New Zealanders live with some form of arthritis, of which $56 \%$ of these people have osteoarthritis. Furthermore, prevalence is expected to reach 1 million by 2040 due to projected increases in the age of the population and the growing obesity rate, factors known to affect the development of osteoarthritis (Access Economics, 2018; Cross et al., 2014; Palazzo et al., 2016). The total estimated cost of arthritis in New Zealand is $\$ 12.2$ billion per year, including $\$ 993$ million in health sector costs, $\$ 1.2$ billion in lost productivity and $\$ 1.6$ billion in formal and informal care (Access Economics, 2018).

There is currently no cure for osteoarthritis, and unlike other forms of arthritis, there are no disease-modifying drugs with proven efficacy available for the condition. The focus of recent research has been on the maintenance of physical function, symptom reduction and limiting disease progression (Hochberg et al., 2015). Exhausting all conservative treatment options is encouraged before more invasive interventions are employed (Hunter, 2017; Van Manen, Nace, \& Mont, 2012; Zhang et al., 2008). Current clinical guidelines recommend the use of nonpharmacological treatments, such as lifestyle change, weight loss, exercise and manual therapy (non-pharmacological), before considering medication or surgery (Bennell, 2013; Bennell \& Hinman, 2011; Dean \& Gormsen Hansen, 2012; Fransen et al., 2015; Merashly \& Uthman, 2012; Van Manen et al., 2012; Zhang et al., 2008). The National Institute for Health and Care Excellence (NICE) Osteoarthritis Guidelines (2014) advocate for a staged progressive model of clinical management, which shows a progression from non-pharmacological to pharmacological to surgical management of osteoarthritis. However, nonpharmacological treatments are underutilised, and while failed conservative management is a prerequisite for surgery, some people are offered joint replacement surgery without having completed appropriate conservative management (Brand et al., 2014; Hunter, 2011; Hunter \& Lo, 2009). The continued focus by some clinicians on the provision of pharmaceutical and surgical treatment options has prompted some researchers to publish editorials arguing that most people with hip and knee osteoarthritis in high-income countries receive substandard care (Hunter, 2011, 2017; Hunter \& Lo, 2009; Hunter, Neogi, \& Hochberg, 2011). Additionally, it has been suggested that some clinicians are guilty of benign neglect because they take a fatalistic view of osteoarthritis or see conservative treatment as ineffective or too complicated for their patients (Brand et al., 2014; Poitras et al., 2010).

Despite the considerable amount of research detailing best practice management for osteoarthritis, many high-income countries, including New Zealand, have been slow to adopt these recommendations (Baldwin, Briggs, Bagg, \& Larmer, 2017; Bennell, Dobson, \& Hinman, 2014; Hunter, 2017). This delay has been attributed, in part, to some of the common myths about the disease (Hunter, 2017). In particular, myths about causative factors, the pathology, assessment and management 
of osteoarthritis abound. This paper aims to challenge the myths commonly attributed to osteoarthritis that limit effective treatment; outline best clinical practice; and encourage physiotherapists to engage with people with osteoarthritis.

\section{MYTHS COMMONLY ATTRIBUTED TO OSTEOARTHRITIS}

Myth 1: Osteoarthritis is just an old person"s disease It is true that the likelihood of having osteoarthritis increases with age, but it is incorrect to claim that it is an "old person's disease" as hip and knee osteoarthritis can also affect younger people (Ackerman, Kemp, Crossley, Culvenor, \& Hinman, 2017). Ackerman et al. (2015) demonstrated the considerable personal burden experienced by younger people (20 to 55 years) with lower limb osteoarthritis, and recommended the provision of targeted services for people in this age group. Furthermore, younger aged people warrant additional attention to reduce the development of comorbidities which may further compromise their well-being (Skou, Pedersen, Abbott, Patterson, \& Barton, 2018). Hence, it is false to solely attribute the development of the disease to increasing age as its aetiology is multi-factorial (Hochberg et al., 2015). The exact association between osteoarthritis and increasing age is complex and not currently fully comprehended (Hochberg et al., 2015). Increasing age can lead to thinning and fracture of the cartilage covering the articular surfaces of the joints. These changes can result in joint laxity, predisposing the joint to increased shear stresses and injury, promoting progression of the disease (Cross et al., 2014; Hochberg et al., 2015).

However, many factors other than age are associated with an increased chance of developing osteoarthritis. These include gender, obesity, genetics, joint structure, a history of injury and occupation (Palazzo et al., 2016). Osteoarthritis is characteristically more prevalent in women than men, with an odds ratio of 1.6 (95\% confidence interval [Cl] 1.4-2.1) (Silverwood et al., 2015). The reason for this is linked to differences in hormones, joint alignment, cartilage volume and muscle strength (Cross et al., 2014). People who are obese are 2.7 times more likely $(95 \% \mathrm{Cl} 2.2-3.3)$ to have knee osteoarthritis than people who are not obese (Silverwood et al., 2015). Increased body weight is believed to cause additional joint loading and damage (Bliddal, Leeds, \& Christensen, 2014) as well as to contribute to systemic inflammation (Piva et al., 2015). Previous hip or knee joint injury is strongly associated with the development of osteoarthritis (Hochberg et al., 2015). Rupture of the anterior cruciate ligament predictably leads to the development of knee osteoarthritis in $13 \%$ of people within 10 to 15 years of the injury, and this rate increases to between 20 and $40 \%$ if the injury also includes damage to other ligaments, bone or cartilage (Palazzo et al., 2016). Poor joint alignment is associated with the development of osteoarthritis and more strongly associated with progression of the disease (Cerejo et al., 2002; Sharma et al., 2010). In the hip, joint dysplasia can commonly lead to the early development of osteoarthritic changes (Jacobsen \& Sonne-Holm, 2005). Additionally, excessive occupational loads have been linked to increased risk of disease development, especially if the job or occupation requires a lot of kneeling, squatting, lifting or climbing (Palmer, 2012).
Practice point myth 1: Osteoarthritis can affect younger people and should be considered as a provisional diagnosis where there are appropriate signs and symptoms.

Myth 2: Osteoarthritis is just joint wear and tear Osteoarthritis is commonly typified by structural cartilage changes. However, there are also changes in the muscles, bone and synovial tissue at the joint. Hence, it may be best to conceptualise osteoarthritis as a syndrome or a collection of signs and symptoms. The pathology of osteoarthritis is multifaceted, and many different factors contribute to the joint degeneration that occurs (Dell'Isola, Allan, Smith, Marreiros, \& Steultjens, 2016). These include biomechanical overload, structural changes of the cartilage, metabolic mechanisms, inflammatory processes and genetic traits. While mechanical factors are known to be necessary for the development of osteoarthritis, it is still unclear what role the other factors play (Hochberg et al., 2015). Osteoarthritis is known to be a metabolically active disease, and changes can also occur within the peripheral and central nervous systems, which may explain non-mechanical pain symptoms described by some people with osteoarthritis (Cruz-Almeida et al., 2013; Mease, Hanna, Frakes, \& Altman, 2011; Mills, Hübscher, O'Leary, \& Moloney, 2019; Skou et al., 2018).

In contrast to the notion that the joint is wearing out, moderate levels of physical activity and exercise are believed to be protective against the development of hip and knee osteoarthritis (Bennell \& Hinman, 2011; Fransen et al., 2015; Skou et al., 2018). Normally functioning muscles have a protective effect on joints as they distribute load across the joint and help to maintain postural alignment (Bennell, Wrigley, Hunt, Lim, \& Hinman, 2013). Furthermore, there is a plethora of studies demonstrating that improving muscle function with exercise can reduce pain and improve function for people with hip and knee osteoarthritis (Fransen et al., 2015; Hochberg et al., 2012; Hunter \& Lo, 2009; Loew et al., 2012; Skou et al., 2018). Conversely, weak muscles at or around joints can lead to the development of osteoarthritis due to a higher chance of injury and altered load management (Hochberg et al., 2015).

Practice point myth 2: Osteoarthritis is not "just" joint wear and tear. The disease is better conceptualised as a syndrome that includes joint wear and failed repair. Hence, it is essential to avoid describing or referring to osteoarthritis as "wear and tear" when speaking with patients.

\section{Myth 3: The worse the imaging looks, the worse the joint is}

Imaging, such as radiographs and magnetic resonance imaging (MRI), is a standard tool used to diagnose osteoarthritis.

However, only half of the people with radiographic osteoarthritis (visible $x$-ray changes) have clinical symptoms (Jordan et al., 2007; Phan et al., 2005). As such, the assessment of a person's signs and symptoms may be more clinically relevant than the imaging findings. Furthermore, clinical guidelines suggest that requesting an $\mathrm{x}$-ray is not required to make the diagnosis of osteoarthritis and is potentially problematic as it reinforces a mechanical view of the disease (Bennell, 2013; Hunter, 2017; McAlindon et al., 2014; National Institute for Health and Care Excellence, 2015). In most cases, the diagnosis of hip or knee 
joint osteoarthritis can be made by considering the signs and symptoms that a person presents with (Hochberg et al., 2015). Imaging should only be considered when appraising a person's appropriateness for surgery or when ruling out other potential pathologies.

Practice point myth 3: Consider the additional merit of imaging carefully. Radiographic changes can correlate poorly with symptoms and lead to unnecessary interventions. Take care when describing imaging findings to people with osteoarthritis. For example, avoid using terminology such as "degeneration" or "bone on bone" that may incite fear-avoidance behaviours or the belief that nothing can be done to manage the symptoms of osteoarthritis.

Myth 4: Osteoarthritis is the non-inflammatory arthritis Osteoarthritis was traditionally considered to be noninflammatory arthritis, but the presence of inflammatory processes are now acknowledged (Berenbaum, 2013). Synovial tissue inflammation is believed to be one of the key intraarticular processes that contributes to nociception and the subsequent pain experience, with the inflammatory changes leading to intraarticular swelling (Felson et al., 2016). Moreover, extraarticular structures can also become inflamed and contribute to the generation of nociceptive input (Hochberg et al., 2015). Low-grade chronic inflammation may be a consequence of knee injury, or induced by metabolic syndrome or inflammaging (age-associated inflammation), all of which are known risk factors for the development of knee osteoarthritis (Berenbaum, 2013). Recent research has suggested a relationship between osteoarthritis and metabolic disorders (Da Costa et al., 2012; Mills et al., 2019). While the exact link is not yet fully understood, a high body mass index and cardiometabolic disease are associated with systemic inflammation, and it is this systemic inflammation which is thought to influence osteoarthritis (Mills et al., 2019). Some researchers have argued that metabolic-osteoarthritis should be described as a distinct category or phenotype of osteoarthritis (Dell'Isola et al., 2016; Deveza et al., 2017). Of note is that exercise is known to reduce systemic inflammation, which may explain why physical activity positively affects pain and function for people with osteoarthritis (Skou et al., 2018).

Practice point myth 4: Exercise can be beneficial in reducing inflammation for people with osteoarthritis, and physiotherapists can play a key role in prescribing exercise programmes. Additionally, physiotherapists should consider engaging the patient's general practitioner for an analgesic review when medication is considered appropriate.

Myth 5: Conservative treatments are ineffectual and only designed to delay joint replacement surgery

Education, lifestyle and dietary changes, and exercise are the cornerstone of management for people with osteoarthritis (Bennell, 2013; Fransen et al., 2015; Hochberg et al., 2015; Hunter \& Lo, 2009). The focus of treatment for a person with osteoarthritis should be on the maintenance of physical function, modification of symptoms and limiting disease progression (Fransen et al., 2015; Hochberg et al., 2015). Treatment options should be employed progressively, starting with more conservative treatments (exercise, weight loss, education), and then progressing to pharmacological and more invasive interventions (medication, surgery) as needed, while incorporating patient preferences (Fransen et al., 2015; Larmer, Reay, Aubert, \& Kersten, 2014; National Institue for Health and Care Excellence, 2015). In particular, there is abundant high-quality evidence supporting exercise-based treatments for people with hip and knee osteoarthritis (Bennell \& Hinman, 2011; Fransen et al., 2015). Research shows that exercise can positively influence pain, muscle function, body weight, cardiovascular fitness, mood and disease progression (Bartholdy et al., 2017; Bennell et al., 2014; Fransen et al., 2015; Kujala, 2009; Zhang et al., 2008), regardless of the structural changes and symptom severity. The addition of joint mobilisation and manipulation to exercise programmes may also be beneficial (Fitzgerald et al., 2016; Pinto et al., 2013).

Two of the biggest limitations to the efficacy of exercise-based treatment are prescription and patient adherence. Poor exercise prescription for people with knee osteoarthritis can result in either overloading the affected joint, leading to increases in pain and swelling; or more commonly, prescribed exercises that are not challenging enough to facilitate a training effect (Brosseau et al., 2016; Fransen et al., 2015; Hunter, 2017). The inclusion of strategies to improve the adherence to the prescribed exercises could boost treatment effectiveness (Bennell et al., 2014; O’Brien, Bassett, \& McNair, 2013). Physiotherapists should consider employing strategies that assist people to begin and sustain new behaviours that improve their osteoarthritis (Bassett, 2015). Furthermore, as osteoarthritis is a chronic disease, treatment should be viewed as a continuum of care; hence, booster sessions should be considered to assist in the maintenance of regular exercise (Brand, Ackerman, Bohensky, \& Bennell, 2013; Rosemann, Laux, Szecsenyi, \& Grol, 2008).

Practice points myth 5: Exercise, education and weight loss (where appropriate) are essential interventions for all people with osteoarthritis, regardless of disease progression or symptom severity. Prescribed exercises or physical activity programmes should be collaboratively designed, should challenge the patient and promote a training response, and should incorporate strategies to enhance adherence. Joint mobilisation may also be beneficial if clinically indicated.

Myth 6: Discussing weight loss with people with osteoarthritis is outside my scope of practice Increased body weight is a known risk factor for the development of lower limb osteoarthritis, and obesity is commonly associated with progression of the condition (Chapple, Nicholson, Baxter, \& Abbott, 2011; Jacobs, Vranceanu, Thompson, \& Lattermann, 2018; Palazzo et al., 2016; Silverwood et al., 2015). Furthermore, obesity is associated with more negative treatment outcomes (Bliddal et al., 2014). Weight loss is strongly recommended for people with obesity and osteoarthritis, not only to decrease joint loading, but also to counteract the inflammatory effects of metabolically active tissue (Chapple et al., 2011; Cicuttini \& Wluka, 2016; Jacobs et al., 2018; Palazzo et al., 2016; Silverwood et al., 2015). Reducing body weight can significantly lessen a person's likelihood of developing osteoarthritis. Critically, a reduction of $\geq 10 \%$ of body weight can lead to considerable reductions in 
pain for people who already have the disease (Atukorala et al., 2016). While some physiotherapists may believe that discussing weight loss with a patient is outside their scope of practice, physiotherapists are well placed to assist people with making lifestyle changes that will contribute to weight loss.

Practice point myth 6: Obesity is a known modifiable risk factor for osteoarthritis, and physiotherapists should provide support to people embarking on a weight loss programme or refer them on to the appropriate health professional, e.g. dietician or exercise physiologist.

\section{Myth 7: Joint replacement surgery is inevitable} Total joint replacement (TJR) continues to be a valid treatment option for people with advanced hip and knee osteoarthritis, but TJR surgery is not appropriate for everyone with osteoarthritis (Gustafsson, Ekman, Ponzer, \& Heikkilä, 2010; Gwynne-Jones, Gray, Hutton, Stout, \& Abbott, 2018; Parsons, Godfrey, \& Jester, 2009). Disease progression differs from person to person, and many people may never reach the point where TJR surgery is appropriate or necessary. Chapple et al. (2011) identified that disease progression is multifactorial, with predictive factors including increasing age, varus knee alignment, radiographic changes, high body mass index and the presence of the disease at multiple joints. Additionally, not everyone benefits from joint replacement surgery, with a substantial portion of people continuing to report long-term joint pain after surgery (Beswick, Wylde, Gooberman-Hill, Blom, \& Dieppe, 2012; Lingard, Katz, Wright, \& Sledge, 2004). Further research is needed to identify people most likely to benefit from surgical intervention (Rice et al., 2018).

Practice point myth 7: Physiotherapists should only consider referring a person for orthopaedic review (TJR) after the patient has failed an appropriate exercise programme that meets best practice clinical guidelines (Brosseau et al., 2016; Fransen et al., 2015).

\section{WHAT DOES THE FUTURE HOLD FOR OSTEOARTHRITIS MANAGEMENT?}

Exercise, education and weight loss are recommended in several clinical guidelines (Larmer et al., 2014); however these treatment options are not consistently or routinely offered to people with osteoarthritis in primary care (Haskins, Henderson, \& Bogduk, 2014; Hunter, 2017; Runciman et al., 2012). Within New Zealand, the general practitioner is often the first, and most commonly consulted health professional for osteoarthritis (Jolly, Bassett, O'Brien, Parkinson, \& Larmer, 2017). However, a multi-faceted approach of exercise, education and lifestyle advice is needed to provide effective, evidence-informed care for people with osteoarthritis. There is clearly a need for a multidisciplinary approach.

Primary care management of osteoarthritis in New Zealand, at present, is fragmented and episodic, and considerable evidence-to-practice gaps exist. Calls have been made for an osteoarthritis model of care in New Zealand, which would provide a framework for implementing evidence-informed care within the New Zealand primary care system (Baldwin et al., 2017). The term "model of care" refers to an evidence-informed framework or policy that outlines the ideal development and delivery of principles of care within a health system. A model of care goes one step further than clinical guidelines by not only outlining what the care components should be, but also how to deliver them within a particular health system (Briggs, Towler, Speerin, \& March, 2014). An osteoarthritis model of care would incorporate chronic care principles such as multi-disciplinary management, collaborative care planning and self-management strategies.

In Australia, experienced physiotherapists are employed as musculoskeletal coordinators within the New South Wales Osteoarthritis Chronic Care Program Model of Care (Briggs et al., 2014). These musculoskeletal coordinators perform initial assessments of people with osteoarthritis and link these patients to relevant health professionals within the multi-disciplinary team as well as provide overall leadership of the programme at each site. With expertise in exercise prescription and chronic pain management, physiotherapists are ideally positioned to coordinate and lead person-centred care within a New Zealand osteoarthritis model of care (Baldwin et al., 2017); upskilling and/or extended scope of practice roles could be required. As an example, the New Zealand government's Mobility Action Programme (MAP) is supporting multi-disciplinary, communitybased teams to provide early management for people with osteoarthritis (Ministry of Health, 2018). While the MAP represents a positive step towards optimising osteoarthritis management in primary care, formal policy support is needed to upscale this programme and develop an osteoarthritis model of care that would facilitate provision of equitable care to all New Zealanders.

\section{CONCLUSION}

Many myths exist about osteoarthritis, and some will limit the potential benefits that people may gain from conservative treatment. Busting these myths will lead to a better understanding of osteoarthritis and could contribute to better outcomes for people living with the disease. Physiotherapists are well placed to do this through effective education of patients and other healthcare professionals, and by leading the implementation of best-practice care.

\section{KEY POINTS}

1. Many myths and misconceptions exist about osteoarthritis that can have a negative impact on how it is managed and thus outcomes.

2. As physiotherapists, we should explore osteoarthritis beliefs of our patients to identify and clarify potential misconceptions about the disease.

\section{DISCLOSURES}

No additional funding was obtained to support the production of this manuscript beyond the usual academic salaries of the authors.

The authors have no conflicts of interest that merit declaration.

\section{ADDRESS FOR CORRESPONDENCE}

Dr Daniel W. O'Brien, Physiotherapy Department, School of Clinical Sciences, Auckland University of Technology, Akoranga Drive, Northcote, Auckland. Telephone: +64 99219999 ext. 8707. Email: dobrien@aut.ac.nz 


\section{REFERENCES}

Access Economics. (2018). The economic cost of arthritis in New Zealand in 2018: Arthritis New Zealand. New Zealand: Delottes. Retrieved from https://www.arthritis.org.nz/wp-content/uploads/2018/09/Economic-costof-Arthritis-in-New-Zealand-2018.pdf

Ackerman, I. N., Bucknill, A., Page, R. S., Broughton, N. S., Roberts, C., Cavka, B. .... Brand, C. A. (2015). The substantial personal burden experienced by younger people with hip or knee osteoarthritis. Osteoarthritis and Cartilage, 23(8), 1276-1284. https://doi.org/10.1016/j. joca.2015.04.008

Ackerman, llana N., Kemp, J. L., Crossley, K. M., Culvenor, A., \& Hinman, R. S. (2017). Hip and knee osteoarthritis affects younger people, too. Journal of Orthopaedic \& Sports Physical Therapy, 47(2), 67-79. https://doi. org/10.2519/jospt.2017.7286

Atukorala, I., Makovey, J., Lawler, L., Messier, S. P., Bennell, K., \& Hunter, D. J. (2016). Is there a dose-response relationship between weight loss and symptom improvement in persons with knee osteoarthritis? Arthritis Care \& Research, 68(8), 1106-1114. https://doi.org/10.1002/acr.22805

Baldwin, J., Briggs, A. M., Bagg, W., \& Larmer, P. J. (2017). An osteoarthritis model of care should be a national priority for New Zealand. New Zealand Medical Journal, 130(1467), 78-86.

Bartholdy, C., Juhl, C., Christensen, R., Lund, H., Zhang, W., \& Henriksen, M. (2017). The role of muscle strengthening in exercise therapy for knee osteoarthritis: A systematic review and meta-regression analysis of randomized trials. Seminars in Arthritis and Rheumatism. https://doi. org/10.1016/j.semarthrit.2017.03.007

Bassett, S. F. (2015). Bridging the intention-behaviour gap with behaviour change strategies for physiotherapy rehabilitation non-adherence. New Zealand Journal of Physiotherapy, 43(3), 105-111. https://doi.org/do 10.15619/NZJP/43.3.05

Bennell, K. (2013). Physiotherapy management of hip osteoarthritis. Journal of Physiotherapy, 59(3), 145-157. https://doi.org/10.1016/S18369553(13)70179-6

Bennell, K. L., Dobson, F., \& Hinman, R. S. (2014). Exercise in osteoarthritis: Moving from prescription to adherence. Best Practice \& Research Clinical Rheumatology, 28(1), 93-117. https://doi.org/10.1016/j.berh.2014.01.009

Bennell, K. L., \& Hinman, R. S. (2011). A review of the clinical evidence for exercise in osteoarthritis of the hip and knee. Journal of Science and Medicine in Sport, 14(1), 4-9. https://doi.org/10.1016/j.jsams.2010.08.002

Bennell, K. L., Wrigley, T. V., Hunt, M. A., Lim, B.-W., \& Hinman, R. S. (2013). Update on the role of muscle in the genesis and management of knee osteoarthritis. Rheumatic Diseases Clinics of North America, 39(1), 145176. https://doi.org/10.1016/j.rdc.2012.11.003

Berenbaum, F. (2013). Osteoarthritis as an inflammatory disease (osteoarthritis is not osteoarthrosis!). Osteoarthritis and Cartilage, 21(1), 16-21. https://doi.org/10.1016/j.joca.2012.11.012

Beswick, A. D., Wylde, V., Gooberman-Hill, R., Blom, A., \& Dieppe, P. (2012). What proportion of patients report long-term pain after total hip or knee replacement for osteoarthritis? A systematic review of prospective studies in unselected patients. BMJ Open, 2(1), e000435. https://doi.org/10.1136/ bmjopen-2011-000435

Bliddal, H., Leeds, A. R., \& Christensen, R. (2014). Osteoarthritis, obesity and weight loss: evidence, hypotheses and horizons - a scoping review. Obesity Reviews, 15(7), 578-586. https://doi.org/10.1111/obr.12173

Brand, C., Ackerman, I. N., Bohensky, M. A., \& Bennell, K. L. (2013). Chronic disease management: A review of current performance across quality of care domains and opportunities for improving osteoarthritis care. Rheumatic Disease Clinics of North America, 39(1), 123-143. https://doi. org/10.1016/j.rdc.2012.10.005

Brand, C., Harrison, C., Tropea, J., Hinman, R. S., Britt, H., \& Bennell, K. (2014). Management of osteoarthritis in general practice in Australia. Arthritis Care \& Research, 66(4), 551-558. https://doi.org/10.1002/ acr.22197
Briggs, A. M., Towler, S. C. B., Speerin, R., \& March, L. M. (2014). Models of care for musculoskeletal health in Australia: now more than ever to drive evidence into health policy and practice. Australian Health Review, 38(4), 401-405.

Brosseau, L., Wells, G. A., Pugh, A. G., Smith, C. A., Rahman, P., Àlvarez Gallardo, I. C., ... Longchamp, G. (2016). Ottawa Panel evidence-based clinical practice guidelines for therapeutic exercise in the management of hip osteoarthritis. Clinical Rehabilitation, 30(10), 935-946. https://doi. org/10.1177/0269215515606198

Cerejo, R., Dunlop, D. D., Cahue, S., Channin, D., Song, J., \& Sharma, L. (2002). The influence of alignment on risk of knee osteoarthritis progression according to baseline stage of disease. Arthritis and Rheumatism, 46(10), 2632-2636. https://doi.org/10.1002/art.10530

Chapple, C. M., Nicholson, H., Baxter, G. D., \& Abbott, J. H. (2011). Patient characteristics that predict progression of knee osteoarthritis: a systematic review of prognostic studies. Arthritis Care \& Research, 63(8), 1115-1125. https://doi.org/10.1002/acr.20492

Cicuttini, F. M., \& Wluka, A. E. (2016). Not just loading and age: the dynamics of osteoarthritis, obesity and inflammation. The Medical Journal of Australia, 204(2), 47. https://doi.org/10.5694/mja15.01069

Cross, M., Smith, E., Hoy, D., Nolte, S., Ackerman, I., Fransen, M., .. March, L. (2014). The global burden of hip and knee osteoarthritis: estimates from the global burden of disease 2010 study. Annals of the Rheumatic Diseases, 73(7), 1323-1330. https://doi.org/10.1136/ annrheumdis-2013-204763

Cruz-Almeida, Y., King, C. D., Goodin, B. R., Sibille, K. T., Glover, T. L., Riley, J. L., ... Fillingim, R. B. (2013). Psychological profiles and pain characteristics of older adults with knee osteoarthritis. Arthritis Care \& Research, 65(11), 1786-1794. https://doi.org/10.1002/acr.22070

Da Costa, L. A., Arora, P., García-Bailo, B., Karmali, M., El-Sohemy, A., \& Badawi, A. (2012). The association between obesity, cardiometabolic disease biomarkers, and innate immunity-related inflammation in Canadian adults. Diabetes, Metabolic Syndrome and Obesity: Targets and Therapy, 5, 347-355. https://doi.org/10.2147/DMSO.S35115

Dean, E., \& Gormsen Hansen, R. (2012). Prescribing optimal nutrition and physical activity as first-line interventions for best practice management of chronic low-grade inflammation associated with osteoarthritis: Evidence synthesis. Arthritis, 2012, e560634. https://doi.org/10.1155/2012/560634

Dell'Isola, A., Allan, R., Smith, S. L., Marreiros, S. S. P., \& Steultjens, M. (2016). Identification of clinical phenotypes in knee osteoarthritis: A systematic review of the literature. BMC Musculoskeletal Disorders, 17 425. https://doi.org/10.1186/s12891-016-1286-2

Deveza, L. A., Melo, L., Yamato, T. P., Mills, K., Ravi, V., \& Hunter, D. J. (2017). Knee osteoarthritis phenotypes and their relevance for outcomes: A systematic review. Osteoarthritis and Cartilage. https://doi.org/10.1016/j. joca.2017.08.009

Felson, D. T., Niu, J., Neogi, T., Goggins, J., Nevitt, M. C., Roemer, F., MOST Investigators Group. (2016). Synovitis and the risk of knee osteoarthritis: the MOST Study. Osteoarthritis and Cartilage, 24(3), 458464. https://doi.org/10.1016/j.joca.2015.09.013

Fitzgerald, G. K., Fritz, J. M., Childs, J. D., Brennan, G. P., Talisa, V., Gil, A. Abbott, J. H. (2016). Exercise, manual therapy, and use of booster sessions in physical therapy for knee osteoarthritis: A multi-center, factorial randomized clinical trial. Osteoarthritis and Cartilage. https://doi org/10.1016/j.joca.2016.03.001

Fransen, M., McConnell, S., Harmer, A. R., Van der Esch, M., Simic, M., \& Bennell, K. L. (2015). Exercise for osteoarthritis of the knee. The Cochrane Database of Systematic Reviews, 1, CD004376. https://doi. org/10.1002/14651858.CD004376.pub3

Gustafsson, B. Å., Ekman, S.-L., Ponzer, S., \& Heikkilä, K. (2010). The hip and knee replacement operation: an extensive life event. Scandinavian Journal of Caring Sciences, 24(4), 663-670. https://doi.org/10.1111/j.14716712.2009.00759.x 
Gwynne-Jones, D. P., Gray, A. R., Hutton, L. R., Stout, K. M., \& Abbott, J. H. (2018). Outcomes and factors influencing response to an individualized multidisciplinary chronic disease management program for hip and knee osteoarthritis. The Journal of Arthroplasty. https://doi.org/10.1016/j. arth.2018.04.011

Hall, M., Migay, A.-M., Persad, T., Smith, J., Yoshida, K., Kennedy, D., \& Pagura, S. (2008). Individuals' experience of living with osteoarthritis of the knee and perceptions of total knee arthroplasty. Physiotherapy Theory and Practice, 24(3), 167-181. https://doi.org/10.1080/09593980701588326

Haskins, R., Henderson, J. M., \& Bogduk, N. (2014). Health professional consultation and use of conservative management strategies in patients with knee or hip osteoarthritis awaiting orthopaedic consultation. Australian Journal of Primary Health, 20(3), 305-310. https://doi. org/10.1071/PY13064

Hawker, G., French, M. R., Waugh, E. J., Gignac, M. a. M., Cheung, C., \& Murray, B. J. (2010). The multidimensionality of sleep quality and its relationship to fatigue in older adults with painful osteoarthritis. Osteoarthritis and Cartilage, 18(11), 1365-1371. https://doi.org/10.1016/j joca.2010.08.002

Hawker, G., Gignac, M. A. M., Badley, E., Davis, A. M., French, M. R., Li, Y., ... Lou, W. (2011). A longitudinal study to explain the pain-depression link in older adults with osteoarthritis. Arthritis Care \& Research, 63(10), 1382-1390. https://doi.org/10.1002/acr.20298

Hochberg, M. C., Altman, R. D., April, K. T., Benkhalti, M., Guyatt, G., McGowan, J., ... American College of Rheumatology. (2012). American College of Rheumatology 2012 recommendations for the use of nonpharmacologic and pharmacologic therapies in osteoarthritis of the hand, hip, and knee. Arthritis Care \& Research, 64(4), 465-474. https:// doi.org/10.1002/acr.21596

Hochberg, M. C., Silman, A., Smolen, J., Weinblatt, M., \& Weisman, M (2015). Rheumatology (4thed., Vols 1-2). Philapelphia, USA: Elsevier.

Hunter, D. J. (2011). Lower extremity osteoarthritis management needs a paradigm shift. British Journal of Sports Medicine, 45(4), 283-288. https:// doi.org/10.1136/bjsm.2010.081117

Hunter, D. J. (2017). Osteoarthritis management: Time to change the deck. The Journal of Orthopaedic and Sports Physical Therapy, 47(6), 370-372 https://doi.org/10.2519/jospt.2017.0605

Hunter, D. J., \& Lo, G. H. (2009). The management of osteoarthritis: An overview and call to appropriate conservative treatment. Medical Clinics, 93(1), 127-143. https://doi.org/10.1016/j.mcna.2008.07.009

Hunter, D. J., Neogi, T., \& Hochberg, M. C. (2011). Quality of osteoarthritis management and the need for reform in the US. Arthritis Care \& Research, 63(1), 31-38. https://doi.org/10.1002/acr.20278

Jacobs, C. A., Vranceanu, A.-M., Thompson, K. L., \& Lattermann, C. (2018). Rapid progression of knee pain and osteoarthritis biomarkers greatest for patients with combined obesity and depression: Data from the osteoarthritis initiative. Cartilage, 1947603518777577. https://doi. org/10.1177/1947603518777577

Jacobsen, S., \& Sonne-Holm, S. (2005). Hip dysplasia: a significant risk factor for the development of hip osteoarthritis. A cross-sectional survey. Rheumatology (Oxford, England), 44(2), 211-218. https://doi.org/10.1093/ rheumtology/keh436

Jolly, J., Bassett, S. F., O'Brien, D., Parkinson, C., \& Larmer, P. J. (2017). An exploration of the sequence and nature of treatment options available to people living with osteoarthritis of the hip and/or knee within a New Zealand context. New Zealand Journal of Physiotherapy, 45(2), 90-95. https://doi.org/10.15619/NZJP/45.2.05

Jordan, J. M., Helmick, C. G., Renner, J. B., Luta, G., Dragomir, A. D., Woodard, J., ... Hochberg, M. C. (2007). Prevalence of knee symptoms and radiographic and symptomatic knee osteoarthritis in African Americans and Caucasians: The Johnston County Osteoarthritis Project. The Journal of Rheumatology, 34(1), 172-180.

Kujala, U. M. (2009). Evidence on the effects of exercise therapy in the treatment of chronic disease. British Journal of Sports Medicine, 43(8), 550-555. https://doi.org/10.1136/bjsm.2009.059808
Larmer, P. J., Reay, N. D., Aubert, E. R., \& Kersten, P. (2014). Systematic review of guidelines for the physical management of osteoarthritis. Archives of Physical Medicine and Rehabilitation, 95(2), 375-389. https:// doi.org/10.1016/j.apmr.2013.10.011

Lingard, E. A., Katz, J. N., Wright, E. A., \& Sledge, C. B. (2004). Predicting the outcome of total knee arthroplasty. Journal of Bone and Joint Surgery (American), 86(10), 2179

Loew, L., Brosseau, L., Wells, G. A., Tugwell, P., Kenny, G. P., Reid, R., .. Ottawa Panel. (2012). Ottawa panel evidence-based clinical practice guidelines for aerobic walking programs in the management of osteoarthritis. Archives of Physical Medicine and Rehabilitation, 93(7)، 1269-1285. https://doi.org/10.1016/j.apmr.2012.01.024

McAlindon, T. E., Bannuru, R. R., Sullivan, M. C., Arden, N. K., Berenbaum, F., Bierma-Zeinstra, S. M., ... Underwood, M. (2014). OARSI guidelines for the non-surgical management of knee osteoarthritis. Osteoarthritis and Cartilage, 22(3), 363-388. https://doi.org/10.1016/j.joca.2014.01.003

Mease, P. J., Hanna, S., Frakes, E. P., \& Altman, R. D. (2011). Pain mechanisms in osteoarthritis: Understanding the role of central pain and current approaches to its treatment. The Journal of Rheumatology, 38(8), 15461551. https://doi.org/10.3899/jrheum.100759

Merashly, M., \& Uthman, I. (2012). Management of knee osteoarthritis: An evidence-based review of treatment options. Le Journal Médical Libanais. The Lebanese Medical Journal, 60(4), 237-242.

Mills, K., Hübscher, M., O'Leary, H., \& Moloney, N. (2019). Current concepts in joint pain in knee osteoarthritis. Schmerz (Berlin, Germany), 33(1), 22-29. https://doi.org/10.1007/s00482-018-0275-9

Ministry of Health. (2018). The Mobility Action Programme. Wellington, New Zealand: Ministry of Health. Retrieved from https://www.health.govt.nz/ our-work/preventative-health-wellness/mobility-action-programme

National Institue for Health and Care Excellence. (2015). Osteoarthritis NICE Guidelines (National Standard). London: National Institute of Health and Care Excellence. Retrieved from https://www.nice.org.uk/guidance/qs87/ resources/osteoarthritis-pdf-2098913613253

O'Brien, D., Bassett, S., \& McNair, P. J. (2013). The effect of action and coping plans on exercise adherence in people with osteoarthritis. New Zealand Journal of Physiotherapy, 41(2), 49-57.

Palazzo, C., Nguyen, C., Lefevre-Colau, M.-M., Rannou, F., \& Poiraudeau, S. (2016). Risk factors and burden of osteoarthritis. Annals of Physical and Rehabilitation Medicine, 59(3), 134-138. https://doi.org/10.1016/J rehab.2016.01.006

Palmer, K. T. (2012). Occupational activities and osteoarthritis of the knee. British Medical Bulletin, 102, 147-170. https://doi.org/10.1093/bmb/ Ids012

Parsons, G. E., Godfrey, H., \& Jester, R. F. (2009). Living with severe osteoarthritis while awaiting hip and knee joint replacement surgery. Musculoskeletal Care, 7(2), 121-135. https://doi.org/10.1002/msc.145

Phan, C. M., Link, T. M., Blumenkrantz, G., Dunn, T. C., Ries, M. D., Steinbach, L. S., \& Majumdar, S. (2005). MR imaging findings in the follow-up of patients with different stages of knee osteoarthritis and the correlation with clinical symptoms. European Radiology, 16(3), 608-618. https://doi.org/10.1007/s00330-005-0004-5

Pinto, D., Robertson, M. C., Abbott, J. H., Hansen, P., \& Campbell, A. J. (2013). Manual therapy, exercise therapy, or both, in addition to usual care, for osteoarthritis of the hip or knee. 2: Economic evaluation alongside a randomized controlled trial. Osteoarthritis and Cartilage, 21(10), 1504-1513. https://doi.org/10.1016/j.joca.2013.06.014

Piva, S. R., Susko, A. M., Khoja, S. S., Josbeno, D. A., Fitzgerald, G. K., \& Toledo, F. G. S. (2015). Links between osteoarthritis and diabetes: Implications for management from a physical activity perspective. Clinics in Geriatric Medicine, 31(1), 67-87. https://doi.org/10.1016/j. cger.2014.08.019

Poitras, S., Rossignol, M., Avouac, J., Avouac, B., Cedraschi, C. Nordin, M., ... Hilliquin, P. (2010). Management recommendations for knee osteoarthritis: how usable are they? Joint, Bone, Spine: Revue Du Rhumatisme, 77(5), 458-465. https://doi.org/10.1016/j. jbspin.2010.08.001 
Rice, D. A., Kluger, M., McNair, P. J., Lewis, G. N., Somogyi, A. A.,

Borotkanics, R., ... Walker, M. (2018). Persistent postoperative pain after total knee arthroplasty: a prospective cohort study of potential risk factors. British Journal of Anaesthesia, 121(4), 804-812. https://doi.org/10.1016/j. bja.2018.05.070

Rosemann, T., Laux, G., Szecsenyi, J., \& Grol, R. (2008). The Chronic Care Model: congruency and predictors among primary care patients with osteoarthritis. Quality and Safety in Health Care, 17(6), 442-446. https:// doi.org/10.1136/qshc.2007.022822

Runciman, W. B., Hunt, T. D., Hannaford, N. A., Hibbert, P. D., Westbrook, J. I., Coiera, E. W., ... Braithwaite, J. (2012). CareTrack: assessing the appropriateness of health care delivery in Australia. The Medical Journal of Australia, 197(2), 100-105. https://doi.org/10.5694/mja12.10510

Sharma, L., Song, J., Dunlop, D., Felson, D., Lewis, C. E., Segal, N., ... Nevitt, M. (2010). Varus and valgus alignment and incident and progressive knee osteoarthritis. Annals of the Rheumatic Diseases, 69(11), 1940-1945. https://doi.org/10.1136/ard.2010.129742

Silverwood, V., Blagojevic-Bucknall, M., Jinks, C., Jordan, J. L., Protheroe, J., \& Jordan, K. P. (2015). Current evidence on risk factors for knee osteoarthritis in older adults: A systematic review and meta-analysis Osteoarthritis and Cartilage, 23(4), 507-515. https://doi.org/10.1016/j. joca.2014.11.019

Skou, S. T., Pedersen, B. K., Abbott, J. H., Patterson, B., \& Barton, C. (2018) Physical activity and exercise therapy benefit more than just symptoms and impairments in people with hip and knee ossteoarthritis. The Journal of Orthopaedic and Sports Physical Therapy, 48(6), 439-447. https://doi. org/10.2519/jospt.2018.7877

Van Manen, M. D., Nace, J., \& Mont, M. A. (2012). Management of primary knee osteoarthritis and indications for total knee arthroplasty for general practitioners. The Journal of the American Osteopathic Association, 112(11), 709-715

Zhang, W., Moskowitz, R. W., Nuki, G., Abramson, S., Altman, R. D., Arden, N., ... Tugwell, P. (2008). OARSI recommendations for the management of hip and knee osteoarthritis, Part II: OARSI evidence-based, expert consensus guidelines. Osteoarthritis and Cartilage, 16(2), 137-162. https:// doi.org/10.1016/j.joca.2007.12.013 